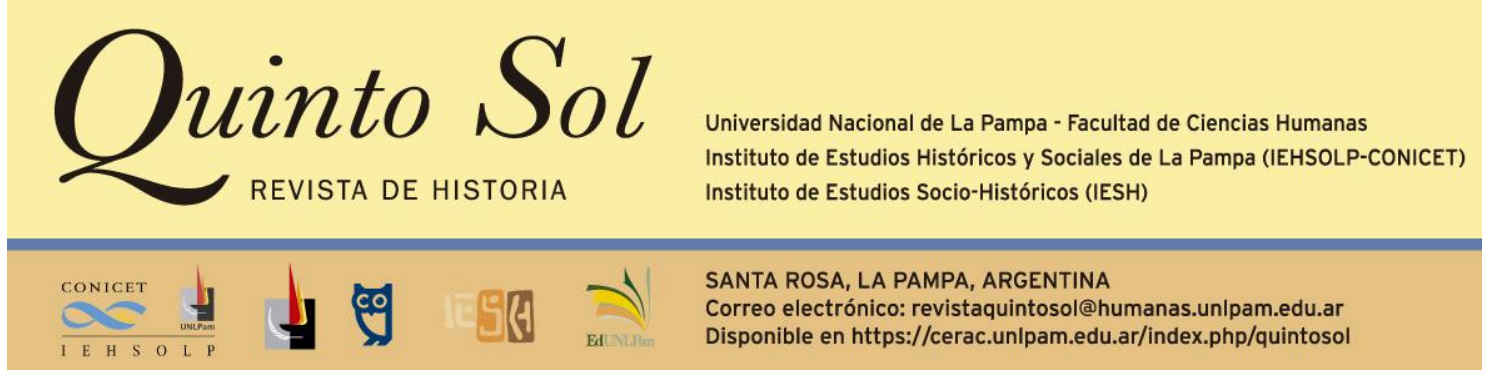

Quinto Sol, vol. 26, n 1, enero-abril 2022, ISSN 1851-2879, pp. 1-20

http://dx.doi.org/10.19137/qs.v26i1.5490

Esta obra se publica bajo licencia Creative Commons 4.0 Internacional. (Atribución-No ComercialCompartir Igual)

\title{
Un entretenimiento ilustrado. Correo del Domingo (1864-1868) y la consolidación de la prensa ilustrada en Buenos Aires
}

\author{
Illustrated entertainment. Correo del Domingo (1864-1868) and \\ the consolidation of the illustrated press in Buenos Aires
}

\section{Um entretenimento ilustrado. Correo del Domingo (1864-1868) e a consolidação da imprensa ilustrada em Buenos Aires}

\section{Diego Labra}

Consejo Nacional de Investigaciones Científicas y Técnicas

Universidad Nacional de La Plata

Argentina

Correo electrónico: diegolabraunlp@yahoo.com.ar

\section{Resumen}

Desde inicios del siglo XXI se consolidó una bibliografía sobre la imagen impresa en el Buenos Aires decimonónico. Sin embargo, Correo del Domingo (1864-1868) no ha sido aún objeto de una investigación de largo aliento, cuando la publicación fundada por José María Cantilo, junto con El Mosquito (1863-1893), hicieron de los años 1860 un punto de inflexión en la historia de la prensa ilustrada porteña.

En este artículo nos concentramos en el análisis de la propuesta editorial del semanario. Identificamos como su mayor innovación formal la de haber reunido recursos dispares que podían encontrarse años antes en el folletín del diario o en periódicos literarios, que confluyeron en una publicación

Palabras clave prensa periódica litografía novela por entregas lectoras 
que dio un salto cualitativo en la experiencia de lectura de prensa y abrió un camino que culminaría en el magazine de entresiglos. Concretamente, analizamos la manera en que se incorporaron al formato semanal géneros discursivos asociados hasta entonces al rodapié del diario (en particular, la novela por entregas), así como un despliegue sin precedentes de imágenes litográficas, a lo largo de una generosa publicación que multiplicaba las acostumbradas cuatro páginas de la prensa contemporánea para atraer un lectorado expandido y diversificado.

\section{Abstract}

Since the beginning of the $21^{\text {st }}$ century, a bibliography on the printed image in 19th century Buenos Aires has been consolidated. However, Correo del Domingo (1864-1868) has not yet been the object of a longterm research, even though the publication founded by José María Cantilo, along with El Mosquito (1863-1893), made the 1860 s a turning point in the history of the local illustrated press.

In this article we will concentrate on the analysis of the editorial configuration of the weekly publication. We identify as its greatest formal innovation the fact that it brought together different resources, which could be found years before in the newspaper's feuilleton or in literary publications, converging in a periodical that made a qualitative leap in the experience of reading the press and opened a path that would culminate in the turn-of-the-century magazine. Specifically, we will analyze how discursive genres associated until then to the newspaper's rezde-chausée (in particular, the serialized novel) were incorporated into the weekly format, as well as an unprecedented display of lithographic images, throughout a generous publication that multiplied the usual four pages of the contemporary press to attract an expanded and diversified readership.

\section{Resumo}

Desde inícios do século XXI, consolidou-se uma bibliografia sobre a imagem impressa no Buenos Aires daquela época. Porém, Correo del Domingo (1864-1868) não tem sido ainda objeto de investigação, quando a publicação fundada por José María Cantilo, junto com El Mosquito (18631893), fizeram do ano 1860 um ponto de inflexão na história da imprensa ilustrada portenha.

Neste artigo nos concentraremos na análise da proposta editorial do semanário. Identificamos como sua maior inovação formal a de ter reunido recursos dispares que podiam encontrar-se anos atrás no folhetim do jornal ou em textos literários os quais confluíram em uma publicação que deu um salto qualitativo na experiência de leitura de imprensa e abriu um caminho que finalizaria no Magazine dentre séculos. Concretamente, analisamos a forma em que se incorporaram ao formato semanal gêneros discursivos associados ao rodapé do jornal (particularmente, a novela por envio ou entrega), assim como a implantação sem precedentes de imagens litográficas, ao longo de uma generosa publicação que multiplicava as quatro páginas da imprensa contemporânea para atrair um leitor expandido e diversificado.

\section{Keywords}

periodic press

lithograph

serial novels

readers

\section{Palavras-chave}

imprensa periódica

litografia

novelas por envio ou entrega leitoras 


\section{Un entretenimiento ilustrado. Correo del Domingo (1864-1868) y la consolidación de la prensa ilustrada en Buenos Aires}

Desde inicios del siglo XXI se ha consolidado una interesante bibliografía sobre la imagen impresa en los periódicos porteños del siglo XIX (Malosetti Costa y Gené, 2009; Szir, 2010; Roman, 2010; Pas 2011, entre otros). En el esbozo de periodización que surge de ella puede identificarse a los años 1860 como un quiebre a partir de la mayor cantidad y longevidad de las publicaciones ilustradas que encontramos en la década. Mas, a pesar de ubicarse como un protagonista de ese punto de inflexión, la primera época de Correo del Domingo (1864-1868) no ha sido aún objeto de una investigación de largo aliento. ${ }^{1}$

Quizá la razón sea que, al imprimirse durante casi un lustro, representa un corpus de más de doscientos ejemplares, considerable en relación a la mayoría de las publicaciones decimonónicas. O tal vez porque, a diferencia del contemporáneo El Mosquito (1863-1893), no representa a primera vista una novedad en comparación con los periódicos que lo preceden. Pero, argumentamos aquí, que justamente por ello es un título importante en el desarrollo de la prensa ilustrada en Buenos Aires. Un impreso semanal que supo combinar el clisé importado desde Europa con la litografía tomada "del natural"; los aires "ilustrados" de la prensa literaria con los géneros literarios que podían leerse en el rodapié de los diarios; el apego por la venta por suscripción, aunque también la innovación de la portada ilustrada. Entendemos, a partir de estos y otros rasgos, que Correo del Domingo fue una suerte de puente, que tomó diversos recursos presentes en otros impresos contemporáneos y los condensó en una propuesta editorial innovadora que sentó un antecedente directo del magazine masivo del período de entresiglos (Rogers, 2008).

En este artículo indagaremos cómo se configuró esta propuesta editorial, deteniéndonos en dos aspectos en particular. Primero, el uso protagónico de la imagen impresa, en el que superó, cuantitativa y cualitativamente, a las publicaciones contemporáneas. Segundo, la ampliación del repertorio de recursos propios de un semanario literario, mediante la incorporación de variedades, novelas por entregas y otros textos asociados al folletín, liberados aquí de las limitaciones del zócalo inferior y desplegados a lo largo de dieciséis páginas. Finalmente, hipotetizamos acerca de qué lectores se buscó alcanzar, y de qué manera se lidió con los límites materiales y comerciales que encontraban entonces las publicaciones periódicas ilustradas.

\footnotetext{
${ }^{1}$ La fuente Correo del Domingo fue relevada en la Hemeroteca de la Biblioteca Central de la Universidad Nacional de La Plata, La Plata, Argentina. También existe una colección completa en la Sala del Tesoro de la Biblioteca Nacional, Ciudad Autónoma de Buenos Aires, Argentina, donde está disponible para consulta en formato microfilm.
} 


\section{Una propuesta editorial ambiciosa}

A comienzos del siglo XIX, la circulación de imágenes impresas había estado limitada a la importación desde un mercado europeo mucho más desarrollado (Pas, 2014), fuera en la forma de periódicos ilustrados o de los pequeños "clisés" que se utilizaban en la prensa local (Szir, 2010). En 1826 se instaló el primer establecimiento litográfico de Buenos Aires, primero en manos de Jean-Baptiste Douville y luego de César Hipólito Bacle. El fracaso de ambos es prueba fehaciente de los escollos materiales que aún encontraban tales ambiciones editoriales (Szir, 2010; Pas, 2011). Incluso luego de la Batalla de Caseros, en un clima político signado por la urgencia de reemplazar la iconografía federal por otra centrada en "una patria colectiva y republicana desde los orígenes" (Roman, 2010, p. 157), limitaciones técnicas y comerciales seguían pesando sobre una prensa ilustrada constreñida por una base de lectores demasiado reducida y costos de producción muy altos. Hacia 1860 pueden sentirse vientos de cambio. La oferta editorial se amplió, sostenida por un creciente público lector, producto a su vez del aumento demográfico y las campañas alfabetizadoras: los primeros brotes de lo que en el último cuarto del siglo se convertiría en la revolución de la "industrialización gráfica" (Szir, 2016, p. 50).

El semanario Correo del Domingo. Periódico literario ilustrado, fundado por José María Cantilo (1816-1872) y cuyo número inaugural apareció el primer día de 1864, se encuentra en el punto de origen de ese naciente estado de transformaciones en la prensa porteña. Nacido en Buenos Aires, Cantilo se exilió en Montevideo durante parte del gobierno de Juan Manuel de Rosas, donde hizo sus primeras letras escribiendo en El Comercio del Plata, de Florencio Varela. De regreso en Argentina, desempeñó una serie de cargos públicos a nivel provincial y municipal, entre los que se destaca haber sido electo diputado provincial en 1862 y nuevamente en 1872, función que ejerció hasta el momento de su fallecimiento el 16 de agosto de ese mismo año. Publicó en vida muchas poesías y novelas cortas; colaboró en el diario El Nacional, de Dalmacio Vélez Sársfield, y tradujo a Alexander Hamilton. Entre los varios periódicos que fundó se destacan El Siglo y La Verdad. ${ }^{2}$

En Correo del Domingo, Cantilo ofició como director y principal redactor, acompañado por tres importantes figuras intelectuales: el médico y poeta Ricardo Gutiérrez, el más joven pero ya muy notorio literato y promotor del pensamiento católico José Manuel Estrada y Juan María Gutiérrez. Colaboraron, además, esporádicamente José Mármol, Nicolás Avellaneda, Domingo F. Sarmiento, Santiago Estrada y Bartolomé Mitre, de quien Cantilo fuera partidario en la última década de su vida.

El periódico se presentó a sí mismo como un muestrario de las bellas letras, una plataforma para "nuestra literatura" que serviría para "que los literatos de algun nombre tuviesen el gusto en dar á luz producciones que conservan ignoradas y que ofreciesen nuevos é interesantes trabajos". ${ }^{3}$ Una reputación respaldada por los

\footnotetext{
${ }^{2}$ Cantilo, José María. Biografía del Diputado de la Nación Argentina en el Patrimonio Legislativo del Honorable Congreso de la Nación. https://apym.hcdn.gob.ar/biografias/266

${ }^{3}$ Correo del Domingo, $N^{\circ} 1,1^{\circ}$ de enero de 1864, p. 6 . En adelante, para simplificar la forma de citado en las notas, utilizaremos $C d D$. Todas las citas de $C d D$ y de otros periódicos mencionadas en el artículo respetan la ortografía, sintaxis, y demás aspectos presente en las fuentes originales.
} 
nombres propios arriba listados y amplificada por otros periódicos contemporáneos, ${ }^{4}$ que trascendió hasta nuestros días (Roman, 2010; Szir, 2010).

Efectivamente, podía encontrarse mucha literatura en Correo del Domingo. La sección "Poesia Americana", dirigida por Gutiérrez, ${ }^{5}$ funcionó como una marquesina para autores hispanoamericanos, entre los que se destacó Esteban Echeverría. Asimismo, a fines del septiembre de 1866, se consagró un número completo a la publicación íntegra e ilustrada del poema de Estanislao del Campo, Fausto. Impresiones del gaucho Anastasio el Pollo en la representación de esta ópera. ${ }^{6}$ Pero también es cierto que un análisis del corpus evidencia las diferencias que lo separaban de $L a$ Revista del Plata (1853-1855/1860-1861) o El Plata Científico y Literario (1854-1855), ejemplos célebres de lo que se consideraba entonces un "periódico literario". Podemos concluir que esos extractos promocionales reflejan más la apreciación promovida por propios y terceros, que lo que efectivamente se podía encontrar en las páginas de la publicación.

Entre las muchas presentaciones y preámbulos que incluye el primer número, el más interesante es aquel en el cual Cantilo explicita a "los lectores" su misión editorial. Aseguraba que podría con su impreso satisfacer la demanda de "lecturas amenas" sin ningún tipo de "fin político", Cantilo buscó reclamar ese espacio estrictamente "literario" de la prensa. "Entretener" aparece como un rasgo prestigiado y programático en este texto. El fundador del periódico tenía la convicción de que aquellas lecturas respecto de las cuales la "sociedad intelijente" se mostraba "ávida" eran "principalmente literaria[s]". ${ }^{7}$ Una declaración no disímil a otras elevadas anteriormente, por ejemplo, por un joven Juan Bautista Alberdi en La Moda (1837-1838), pero que aquí alcanzó un nuevo significado al tener correlato en la propuesta editorial.

El diseño a dos columnas de texto espaciadas entre sí sobre una carilla predominantemente blanca buscó dejar en claro desde lo tipográfico que Correo del Domingo articulaba una lectura diferente a la de los diarios, que era compacta y densa. Asimismo, la distribución semanal que, como su título indica, se realizaba el primer día de la semana hablaba de una lectura con otra cadencia que la urgente de la prensa noticiosa. Sus dieciséis páginas con portadas litografiadas exhibían una factura visualmente ambiciosa, y alimentaban el deseo de ser coleccionado, conservado, encuadernado $y$, en el mejor de los casos, releído. Con este fin el paginado siguió una lógica de numeración continua para mantener el sentido de lectura una vez ensamblado cada uno de los ocho volúmenes que conforman los doscientos diez números editados, los cuales se recopilaban aproximadamente cada seis meses junto con un índice analítico incluido con el último ejemplar de cada volumen.

Que un objeto impreso es más que el texto que contiene es una postura analítica que hoy casi no hay que aclarar, gracias a la difusión y aceptación que el trabajo de Roger Chartier (1992) tiene en los estudios de la prensa en la academia local $(y$, a través de este, también aquellos de sus maestros e influencias como Michel De Certau y Donald McKenzie). El periódico debe entenderse como un dispositivo, un artefacto confeccionado desde lo tipográfico y lo material, con el fin de interactuar de manera específica con el lector deseado al cual se busca apelar como interlocutor y

\footnotetext{
${ }^{4}$ El Nacional, $\mathrm{N}^{\circ} 6.091,5$ de noviembre de 1866, p. 2.

${ }^{5}$ El Nacional, $\mathrm{N}^{\circ} 3.989,3$ de noviembre de 1865, p. 4.

${ }^{6} C d D, \mathrm{~N}^{\circ} 144,30$ de septiembre de 1866.

${ }^{7} C d D, N^{\circ} 1,1^{\circ}$ de enero de 1864, p. 6.
} 
consumidor (Pas, 2016). Desde esta mirada, sostenemos que Correo del Domingo se distingue en cuanto aparece como un esfuerzo coordinado por aunar una serie de recursos editoriales disponibles que tentativamente podríamos llamar tecnologías impresas de entretenimiento. Ninguno de estos recursos fue introducido aquí por primera vez, pero al reunirlos en una propuesta editorial cohesiva y exitosa, abrieron una nueva era para las publicaciones orientadas primordialmente a la lectura por entretenimiento. Que aquí, además, estaba dentro de un semanario avalado por el prestigio de las figuras intelectuales que escribían allí y lo suntuoso de la puesta en página.

De hecho, fue el despliegue cuantitativo y cualitativo de la imagen impresa, primero de los puntos que ocupan nuestro análisis, lo que distinguió a Correo del Domingo como la llegada de algo nuevo en la prensa porteña.

\subsection{Litografía: importada, ilustrativa, "al natural"}

Un "huracán en el bosque de Palermo" no solo sacudió la ciudad en 1866, sino que también tomó por asalto el $\mathrm{N}^{\circ} 117$ de Correo del Domingo, el cual incluyó una crónica de cómo el viento "sorprendió á los paseantes sin darles tiempo de tomar precauciones". El escrito fue complementado con una lujosa ilustración del fenómeno meteorológico firmada por Henri Meyer, a doble página y en el centro del periódico. ${ }^{8}$

Imagen 1: Vista de una parte del Bosque de Palermo, al disiparse la oscuridad de la tarde del 19 de marzo de 1866

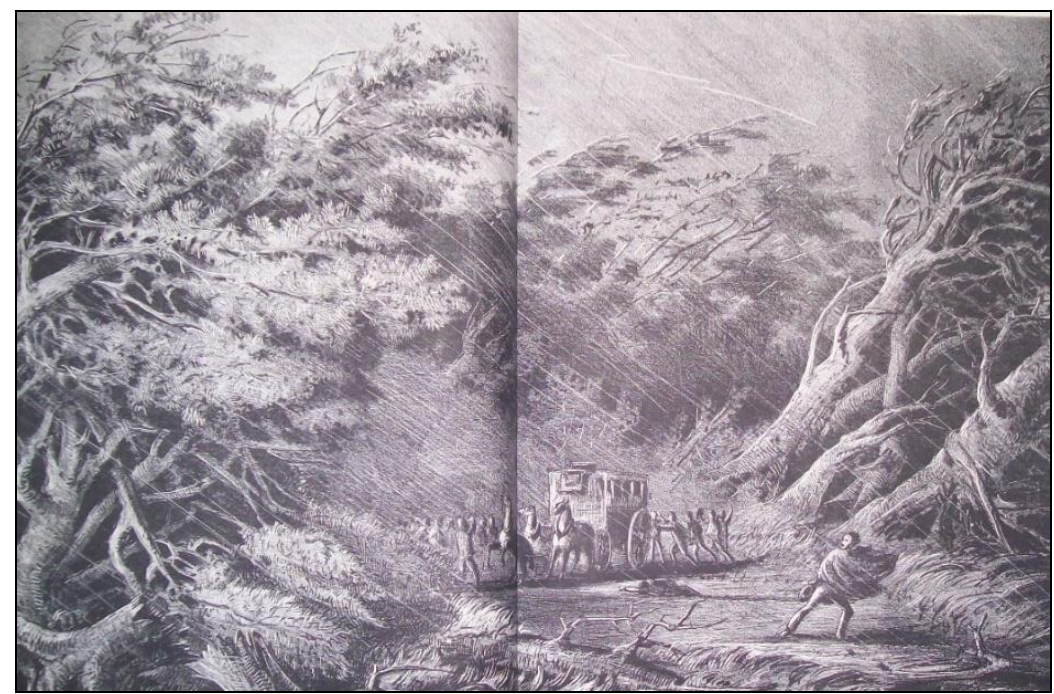

Fuente: $C d D, \mathrm{~N}^{\circ} 117,25$ de marzo de 1866, pp. 199, 200.

¿Qué habrá generado en el lector la posibilidad de vislumbrar por primera vez en un periódico la representación de un acontecimiento ocurrido pocos días antes, desde la comodidad de su hogar (Imagen 1)? La pregunta invita a reflexionar sobre el impacto de la imagen impresa y su "exceso" semiótico, el cual funciona como estímulo emocional en un consumo visual que atrae al lector a mirarlas y a disfrutarlas (Littau, 2008). Como señala Pas (2014), a la imagen, desde la litografía y los grabados a la fotografía hasta la televisión, se le atribuyen poderosas propiedades, desde la

\footnotetext{
${ }^{8} C d D, N^{\circ} 117,25$ de marzo de 1866, pp. 192, 199, 200.
} 
capacidad del empirismo más puro hasta el temible poder de corromper al espectador. Más accesible que la también sospechada novela al no demandar alfabetización para ser consumida, la imagen impresa era capaz de capturar con mayor autoridad la economía de la atención de un lector decimonónico (Crary, 2001); lo cual no la hacía menos compleja, ya que interpretar sus múltiples significados requiere de ciertas competencias. La imagen es inherentemente polisémica, como señaló Roland Barthes (1986), al concentrar diferentes niveles de lectura que, dependiendo quién la vea, aparecen como evidentes o implícitos.

La multiplicidad de la imagen estaba en plena exposición en la Buenos Aires de 1860, en la cual la cultura de lo visible se expandía de manera exponencial. Fuera en salones dedicados a "espectáculos visuales" como "panoramas", "juegos eléctricos" y "espejos deformantes" (Telesca y Amigo, 1997, p. 33), en el "teatro visual" que desplegaba "fantasmagorías" producidas con la "linterna mágica" (Maturana, 2009, p. 83), o en una oferta de periódicos ilustrados que entraría pronto en una etapa expansiva, la imagen tomaba protagonismo. También se volvía un negocio, al hacerse redituable explotar lo que Sandra Szir (2010) llama la "curiosidad y deseo de ver y poseer imágenes" que atacaba a los porteños de la época (p. 1).

Fue justamente a esta "curiosidad y deseo" que Cantilo buscó apelar. Así "como Paris tiene su Ilustracion, y Londres la suya, nosotros podemos decir otro tanto del interesante periódico Correo del Domingo que se publica en esta ciudad", un esfuerzo gráfico que merecía "la protección [es decir, la compra] de la sociedad de Buenos Aires". ${ }^{9}$ Con su generada y variada oferta visual, el semanario fue protagonista en el proceso al introducir un "cambio profundo en los modos de percibir y de leer" un periódico (Pas, 2014, p. 67), el cual ya no incluía solo texto en la página.

Producto de lo que Szir (2017) Ilama la "interculturalidad global de la imagen", de una circulación transatlántica de lo visual impreso, podemos encontrar en las páginas de Correo del Domingo, por ejemplo, que las ilustraciones que acompañaron algunas de las entregas del diario de viajes "De Madrid a Nápoles. Viaje de recreo", ${ }^{10}$ ya habían sido publicadas originalmente en el libro de Pedro Antonio de Alarcón (1861).

Imagen 2: La Catedral de Milán

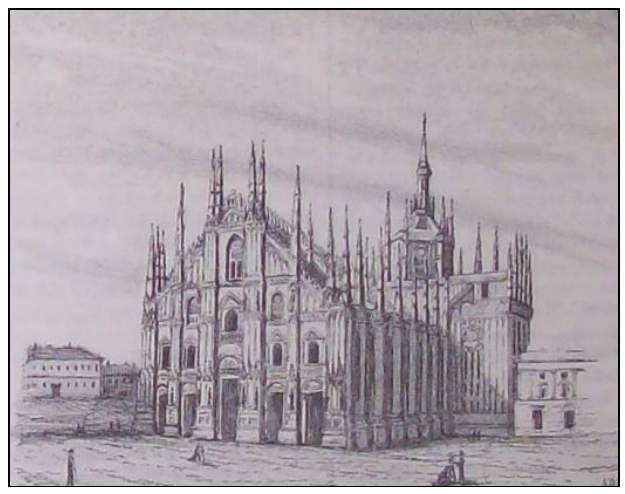

Fuente: $C d D, \mathrm{~N}^{\circ} 165,24$ de febrero de 1867, p. 153.

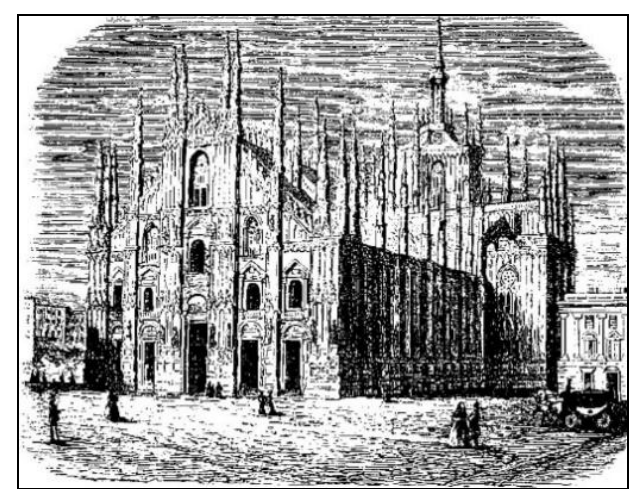

Alarcón, 1861, p. 224.

Como se puede observar en la Imagen 2, el acto de la traducción y reconfiguración fue una operatoria que no solo reproducía el original, sino que

\footnotetext{
${ }^{9}$ El Nacional, N $6.091,5$ de noviembre de 1866, p. 2.

${ }^{10} C d D, N^{\circ} 165,24$ de febrero de 1867, pp. 152, 153.
} 
también producía nuevas (re)creaciones. Incluso antes de la labor del litógrafo, el jefe de redacción ya ejercía su poder en la selección de qué se imprimía y qué no, dado que privilegiaba unos retratos o paisajes sobre otros incluidos en la edición europea original. La elección del mismo texto a serializar pudo haber estado informada por la imagen, y era un punto a favor que la obra contara con ilustraciones que podían ser reproducidas.

Si bien el semanario ofreció "un espectro muy diverso de imágenes" (Roman, 2010, p. 286), existió una predilección por la ilustración. La correlación entre la tapa y el contenido que se encontraba en el interior, así como entre los artículos y las litografías que compartían una página, permiten identificar una propuesta editorial en la cual se privilegió la interacción entre el consumo de texto e imagen, entre lo que se podía leer y ver. Fueron comunes las series en las portadas como, por ejemplo, la que puso el foco en retratos de escritores chilenos como Guillermo Blest Gana o Andrés Bello, cuyas obras podían leerse dentro. ${ }^{11}$

El esfuerzo requerido por esta correspondencia entre tapa y contenido invita a pensar en la novedosa capacidad de hacer encargos "a la medida" al litógrafo a partir de la oferta textual de la semana. O bien a la inversa, a la redacción de material exclusivamente con el fin de que este se ajustara a las imágenes disponibles. No puede negarse que un factor de peso en la selección fue la contingencia propia de condiciones de producción subóptimas y una circulación global que no implicaba la "simetría" entre los diferentes actores involucrados en la travesía (Szir, 2017). En el contexto de un circuito que tenía una sola dirección, de Europa hacia Buenos Aires, la reproducción de las ilustraciones importadas despojaba a la técnica litográfica de una inmediatez que sí poseía en ciudades como París.

De allí la relevancia de la litografía sobre el "huracán" que azotó "el bosque de Palermo" en marzo de 1866, mediante la cual Correo del Domingo ofreció a sus suscriptores lo que presentó como un reportaje visual de la realidad más próxima. Es cierto que la ausencia de hitos visibles en la imagen permite especular que se trata de una copia de un posible original distante, quizás europeo, reutilizado para la ocasión. Pero ya que la apuesta visual fuera verosímil para los lectores es sintomático de los cambios cualitativos que atravesaba la prensa porteña. El establecimiento, a comienzos de la década, de la Imprenta Litográfica del mencionado Meyer, también ilustrador y fundador de El Mosquito (1863-1893), hacía posible creer que uno estaba frente a una ilustración de un evento que había sucedido meros días antes de que la publicación entrara en prensa. Meyer se encargaría del apartado gráfico del semanario hasta su regreso a París en junio de 1867 (Roman, 2010, p. 286), y fue reemplazado tras su partida, entre otros, por Juan Camaña, Juan Schleisinger y, en la impresión de los grabados, el taller litográfico de Jules Pelvilain (Szir, 2010, p. 17).

El despliegue de imágenes presentadas como si fueran tomadas "del natural" posicionó a Correo del Domingo como el impreso idóneo para ocuparse del reportaje gráfico de los principales acontecimientos. Un avance que tensionó la autodefinición inicial del periódico como proveedor de "lecturas amenas", especialmente en los tramos durante los cuales tomó mayor relevancia la Guerra de la Triple Alianza, librada

\footnotetext{
${ }^{11} C d D, N^{\circ} 72,14$ de mayo de 1865, p. 313; $N^{\circ} 78,25$ de junio de 1865, p. 409; $N^{\circ}$ 91, 24 de septiembre de 1865 , p. $617 ; N^{\circ} 99,19$ de noviembre de 1865, p. 745.
} 
por Brasil, Uruguay y Argentina contra Paraguay. ${ }^{12}$ Pero también, la heterodoxa selección de litografías puede entenderse como parte de una estrategia propia de los periódicos ilustrados del siglo XIX, según la cual géneros visuales que nacieron contemporáneamente "bajo la instrumentalidad científica" de las novedosas técnicas fotográficas como el retrato o el "fotoperiodismo de guerra", eran promovidos como "espectáculo de fin de semana para toda la familia" (Guerra, 2010, p. 5). Ante la pluralidad de lo disímil, el simple acto de ver se convertía en un entretenimiento.

Hasta aquí hemos destacado dos características de la oferta visual del periódico: la producción de imágenes presentadas como propias; y la variedad de un repertorio tanto importado como autóctono, que incluyó reportaje gráfico de guerra, crónica visual de la sociabilidad, ilustraciones de textos de ficción y hasta la ocasional caricatura. ${ }^{13}$ Ambas redundan así en una tercera: la desbordante cantidad de imágenes publicadas. De manera fija se ofrecían en la portada (fue el primer periódico porteño en hacerlo), en la contratapa y en las dos páginas centrales, a las que se agregaba una cantidad irregular de grabados dispersos. Hasta la aparición de la nueva Ilustración Argentina (1881-1888), casi quince años después, ninguna publicación porteña volvería a ofrecer tanto para ver.

Encontramos en la litografía de Meyer un particular interés por las "diversiones públicas" y el consumo, que hacía parte del Buenos Aires "visible" en las páginas del Correo del Domingo al mundo de la sociabilidad y consumo urbano. Así lo expresa la primera docena de tapas, las cuales lucieron retratos de artistas cuyas artes podían disfrutarse en la ciudad. Como, por ejemplo, la cantante lírica Carolina Briol, quien "se estrenó en 1857 á los 18 años de edad en diversos teatros, donde siempre fué aplaudida", ${ }^{14}$ o la estrella del Teatro de la Victoria García Delgado, "primer actor y director de la Compañía Dramática". ${ }^{15}$ El despliegue incluyó también copiosa ilustración de modas, un género visual muy frecuentado en la prensa de la época (Hallstead, 2005).

Imagen 3: Salón de las tiendas del "Bazar Filantrópico"

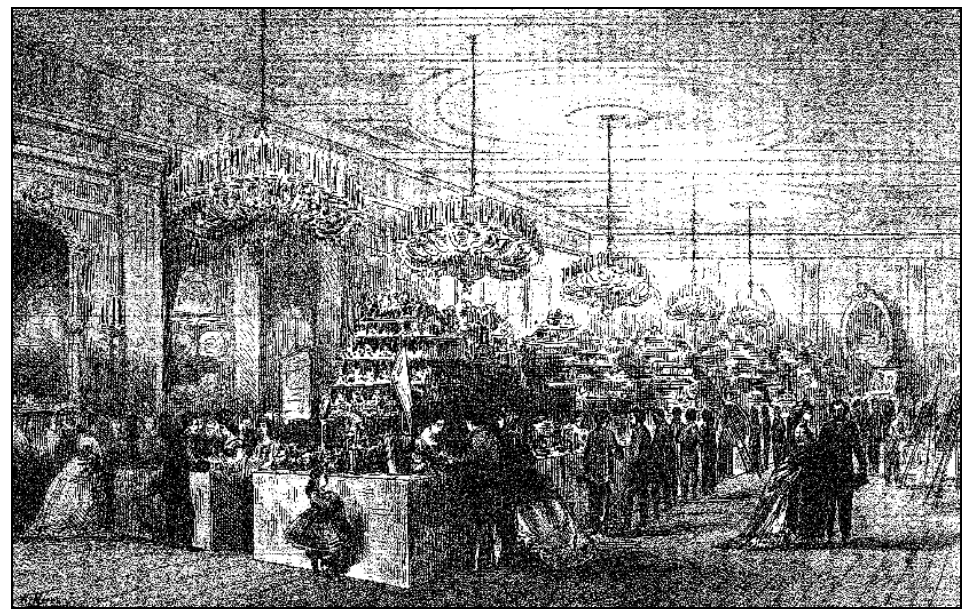

Fuente: $C d D, \mathrm{~N}^{\circ} 98,12$ de noviembre de 1865, p. 744.

\footnotetext{
${ }^{12} C d D, N^{\circ} 71,7$ de mayo de 1865, p. $297 ; N^{\circ} 92,1^{\circ}$ de octubre de 1865, pp. 640,$641 ; N^{\circ} 149,4$ de noviembre de 1867, pp. 276, 277; $N^{\circ} 168,17$ de marzo de 1867, p. 197, entre otros.

${ }^{13} C d D, N^{\circ} 95,22$ de octubre de 1865, p. 696; N²06, 8 de diciembre de 1867, p. 352.

${ }^{14} C d D, N^{\circ} 2,10$ de enero de 1864, p. 17.

${ }^{15} C d D, N^{\circ} 3,17$ de enero de 1864, p. 33.
} 
El mejor ejemplo de esta visibilización de la sociabilidad y el consumo es el extenso reportaje gráfico sobre el "Bazar Filantrópico" (Imagen 3). El evento, desarrollado durante tres días de noviembre de 1865 en los salones del Club del Progreso, epicentro de la vida pública de la alta sociedad de la época (Losada, 2006), fue una "feliz iniciativa del bello sexo" y constó de montar una tienda y un café donde se vendieron objetos donados por ellas y terceros con el fin de recaudar dinero para beneficencia. ${ }^{16}$ El $\mathrm{N}^{\circ} 98$ del semanario, publicado el 12 de noviembre de ese año, estuvo íntegramente consagrado al "Bazar", e incluyó una detallada crónica e ilustraciones alusivas, quizás las más sofisticadas (re)producidas por Meyer para el periódico. En ellas puede observarse el "jardín del bazar", así como el "salón de las tiendas". También se incorporó un plano de las instalaciones.

A décadas de la era de las grandes tiendas como Gath y Chaves o Harrod's (Rocchi, 2006), estas intervenciones visuales equipararon, en la página al menos, al ocio de los sectores pudientes de la ciudad, potencialmente su lectorado, con los paseos y consumos conspicuos ofrecidos por las grand magasins del Viejo Mundo. Todo con el auspicio del Club del Progreso, gran promotor de la sociabilidad europeizante. Como explicitó su presidente, "don Miguel J. Ascuénaga", quien gastó de su propio bolsillo "veinte mil pesos" en las "diversas tiendas", la realización del evento buscó promover una sociabilidad civilizada para las "gentes decentes". ${ }^{17}$

La imagen impresa tuvo un rol central en la construcción del consumidor parisino (Williams, 1982), y las ilustraciones sobre modas y sociabilidad urbana reproducidas en Correo del Domingo parecen querer comprobar esta misma hipótesis para Buenos Aires. En esa clave se puede interpretar también la ilusión de movimiento hacia lugares tan lejanos como deseables a la que invitaban las postales litografiadas de elegantes ciudades europeas que se reproducían en el periódico. Imágenes que atraían en la presumida universalidad de su atractivo y apelaban al público lector a entretenerse en la ensoñación de destinos y objetos deseados, más cercanos que nunca en la combinación indistinta, de página a página, de París, Londres y aquí. Confluyen en el desborde visual del semanario el deseo por ver imágenes, y las imágenes que hacen desear. Una oferta editorial que redundaba en entretenimiento, 0 por lo menos, en una experiencia semiótica que se justifica a sí misma en la fascinación y placer que produce.

Este despliegue hizo de la publicación de Cantilo parte integral de la educación visual del lectorado porteño y de una redefinición del pacto de lectura de la prensa. No solo corroboró el potencial atractivo de la imagen impresa dentro de una propuesta editorial, sino también las posibilidades formales que se abrían con la (re)producción litográfica realizada localmente. Mirar se volvió una parte inseparable de la práctica de leer, lo cual fue particularmente cierto para la lectura por entretenimiento.

\subsection{El folletín desatado: variedades, textos lúdicos y novelas por entregas}

La desbordante variedad visual de Correo del Domingo tuvo un correlato en la propuesta textual. El periódico no contó con demasiadas secciones fijas más allá del editorial "La Semana" (posteriormente, "Revista de la semana" y, más tarde, "Crónica"), donde Cantilo rumiaba sobre el evento más destacado de los pasados siete días bajo el

\footnotetext{
${ }^{16} C d D, \mathrm{~N}^{\circ} 97,5$ de noviembre de 1865, p. 728.

${ }^{17}$ La Tribuna, $\mathrm{N}^{\circ} 3.546,12,13$ y 14 noviembre de 1865, p. 2.
} 
seudónimo "Bruno" (Roman, 2010, p. 286). Alternativamente, la columna podía estar ocupada por temas tan disímiles como la suntuosa función benéfica del "Bazar Filantrópico" o la última noticia llegada desde el frente bélico. En las restantes páginas se encontraba igual diversidad de recursos textuales, muchos de ellos hasta entonces propios del "folletín" de la prensa diaria, como las variedades y las novelas por entregas.

Los géneros "folletinescos" habían surgido de una zona de "contaminación novelesca" y literaria propia de los periódicos franceses durante el primer cuarto del siglo XIX (Molina, 2011, p. 60). Un "espacio para la experimentación, la reapropiación discursiva y, en consecuencia, la invención escrituraria", donde "variedades (varietés), misceláneas (mélanges) y folletín (feuilleton)" fueron términos intercambiables (Pas, 2016, pp. 55, 54). Si bien en la prensa porteña puede rastrearse un proceso afín de experimentación, disperso y difuso, el folletín como un espacio tipográficamente delimitado en el "rodapié" de la primera página fue introducido el 16 de marzo de 1846 con la publicación de "El Judío Errante" de Eugène Sue en el № 4.349 del Diario de la Tarde. En los casi veinte años que siguieron, el folletín se había consagrado como el lugar donde leer novelas por entregas de la mano de importantes diarios como El Nacional, dirigido por Sarmiento, un campeón del recurso (Lettieri, 2006).

Imagen 4: Contratapa de Correo del Domingo

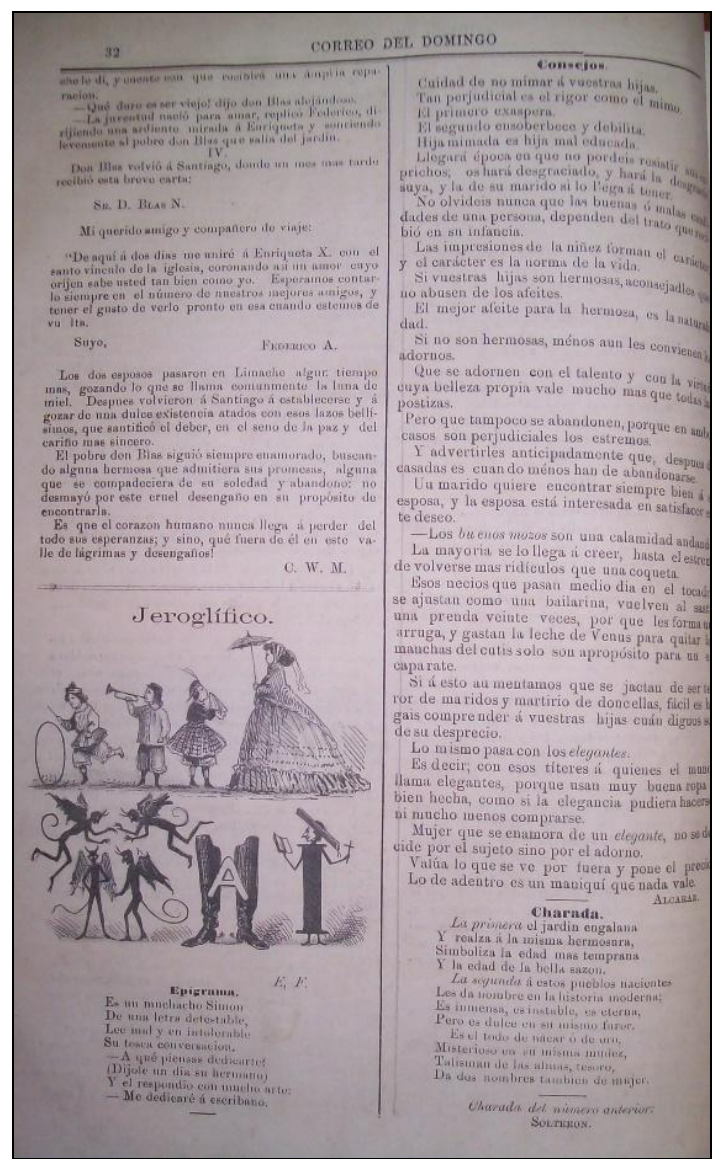

Fuente: $C d D$, l época, № 106, 7 de enero de 1866, p. 32.

Lo mismo se puede decir acerca de los "faitdivers". De trayectoria más difícil de reconstruir (Pas, 2016), sin duda para los años 1860 eran ya parte integral de los diarios 
de gran circulación. ${ }^{18}$ En Correo del Domingo, su inclusión hacia mediados de 1865 se dio como parte de la paulatina consolidación de la última página como un espacio dedicado exclusivamente a una lectura miscelánea (Imagen 4). En el celebratorio $N^{\circ} 100$, un título hizo explícito lo que venía desarrollándose desde hacía algunos meses atrás: la contratapa del periódico se declaró el reino de las "Variedades". ${ }^{19}$

A primera vista, llama la atención la recurrencia de textos lúdicos. "Epigramas", "Charadas", "Enigmas" y "Adivinanzas", todos breves juegos de palabras, se publicaron sin falta en cada número desde su aparición a fines de $1865 .{ }^{20}$ Gracias a los recursos visuales del semanario, aparecen acertijos gráficos como el "Jeroglífico" o el "Logogrifo". ${ }^{21}$ El ejercicio lúdico también introdujo en la contratapa una zona de intercambio -real o ficcional- entre redactores y lectores. Allí puede leerse el reconocimiento a quienes hubiesen resuelto el acertijo y lo hubieran comunicado a la redacción. ${ }^{22}$

Los "faitdivers" pudieron leerse bajo una miríada de títulos como "Noticias diversas", "Variedades", "Consejos", "Frioleras", "Querellas", "Crónica", o "Máximas y pensamientos". ${ }^{23}$ La paleta textual era amplia, desde la lógica de lo curioso y la autonomía narrativa de textos como "Manzano Histórico", donde se relató que "en todas las vidrieras de joyerías en Estados Unidos pueden verse en exhibición brazaletes y otras alhajas hechas de manera adornada con plata oro ó marfil, espresándose que son pedazos del manzano bajo el cual se rindió el jeneral Lee"; a la aspiración aforística de consejos como "Desconfiad de los que se empeñan en pasar por sábios, porque alimentan una enfermedad eterna; y despreciad á los sábios á grande orquesta, porque son fanfarrones é hipócritas". ${ }^{24}$ El único criterio unificador fue la misma diversidad de una prosa deliberadamente breve, fragmentaria y miscelánea.

Víctor Goldgel (2010) señala esta característica de las "variedades" como la expresión más clara de la "heterogeneidad constitutiva" que las distinguía como género periodístico. Por diseño, una respuesta al "deseo de variedad" que "los escritores" le atribuían constantemente un "público" que quería leer "textos cortos y coloridos". La selección de escritos referidos a lugares remotos y situaciones sorprendentes ofrecía una lectura dispersa, poco mediata, orientada a "distender los límites del propio interés -para renovarlo o, simplemente, para distraerse-". Las "variedades" no requerían previo conocimiento sobre la actualidad ni una inmersión en la intertextualidad de diarios políticos y mercantiles, sino que presentaban una lectura menos movida "por el afán de educarse" o informarse "que por el de divertirse" (pp. 276, 278, 279, 280).

En una carta dirigida a Santiago Estrada, Ricardo Gutiérrez reconocía, no sin ironía, que para satisfacer "el delicado paladar de la sociedad moderna" porteña se debía escribir "á lo Dumas, á lo Fernandez Gonzalez, á lo Eguilaz, á lo Pigault-Lebrun". Es decir, había que entretener como autor de novela de folletín y evitar los "sermonazos", pues "cuando uno quiere dormirse con ellos, se entra á cualquier

\footnotetext{
${ }^{18}$ Los Debates, segunda época, № 300, 28 de mayo de 1858, p. 3.

${ }^{19} C d D, \mathrm{~N}^{\circ} 100,26$ de noviembre de 1865, p. 776.

${ }^{20} \mathrm{CdD}, \mathrm{N}^{\circ} 103,17$ de diciembre de 1865, p. 824.

${ }^{21} C d D, N^{\circ} 106,7$ de enero de 1866, p. 32; $N^{\circ} 134,22$ de julio de 1866, p. 32.

${ }^{22} C d D, N^{\circ} 117,25$ de marzo de 1866, p. 224; $N^{\circ} 131,7$ de julio de 1866, p. 32.

${ }^{23} C d D$, I época, $N^{\circ} 106,7$ de enero de 1866, p. 32; $N^{\circ} 116,18$ de marzo de 1866, p. 206; $N^{\circ} 117,25$ de marzo de 1866, p. 224; $\mathrm{N}^{\circ} 124,13$ de mayo de 1866, p. 321; $\mathrm{N}^{\circ} 140,2$ de septiembre de 1866, p. 132.

${ }^{24} C d D$, I época, $\mathrm{N}^{\circ} 116,18$ de marzo de 1866, p. 206.
} 
iglesia". ${ }^{25}$ Las variedades condensaban justamente este atractivo de lo narrativo en bocados fáciles de digerir (Barthes, 2003). Pero el lector que desease una lectura más larga podía encontrarla en la novela por entrega, la cual contaba con el "continuará..." como mecanismo que aspiraba a generar la fidelidad del lector semana a semana ( $y$, tentativamente, hasta el período del próximo pago de la suscripción).

Como citamos antes, Cantilo reconocía una demanda de "lecturas amenas", entre las cuales la "novela tiene mucho favor". ${ }^{26}$ Por eso mismo, el jefe de redacción hizo de ella un eje articulador de la propuesta editorial de Correo del Domingo. Un análisis del corpus arroja que las novelas por entregas ocuparon consistentemente la mitad del espacio disponible, unas ocho páginas semanales. A comienzos de 1867, cuarto y último año de edición, se llegaron a publicar entregas simultáneas de cuatro títulos diferentes: "Dos Destinos", "traducida del frances para el CORREO DEL DOMINGO por la señorita J. M. y dedicada á su padre"; "La felicidad doméstica" de Antonio Trueba; "Esperanza" de Nicolás Granada; y "De Madrid a Nápoles. Viaje de recreo" de Pedro Antonio de Alarcón. ${ }^{27}$

Ante la indefinición de la novela durante sus años formativos (Molina, 2011; Pas, 2016), y de seguro con una saludable vocación comercial, casi todo texto narrativo fue adjetivado como tal. Incluso narraciones con extensiones tan breves como cinco páginas eran presentadas en el semanario como novela. Un ejemplo es "De Madrid a Nápoles", del asiduamente publicado de Alarcón. ${ }^{28}$ La serialización del diario de viaje no solo fue nombrada como una "novela", sino que fue publicitada en otros periódicos a lo largo de los dos años que llevó la publicación de sus sesenta y una entregas ilustradas con postales de las ciudades europeas descritas. ${ }^{29}$

Prácticamente la totalidad de las obras publicadas fueron extranjeras; la única novela de origen nacional de la que tenemos registro es la citada "Esperanza", de Nicolás Granada. ${ }^{30}$ La mayoría fueron europeas y, en particular, peninsulares. Entre los autores se cuentan de Alarcón, Manuel Fernández y González, Enrique Pérez Escrich y Fernán Caballero, seudónimo utilizado por Cecilia Böhl de Faber y Ruiz de Larrea. ${ }^{31}$ Un elenco que incluía a los "folletineros" más famosos de España, cuyas obras se habían impuesto en los rodapiés de diarios como El Nacional o La Tribuna. La novela histórica dominó la oferta literaria, y era la preferida por los letrados porteños al encontrar en ella el beneficio de combinar la enseñanza del pasado con una lectura amena (Parada, 2007).

La publicación de "La Palma del Martirio", anónima y subtitulada "Novela traducida del frances", ${ }^{32}$ delata hasta qué punto la procedencia del país de Dumas y Sue continuaba siendo un atractivo, tanto porque compartía patria con esas luminarias de la literatura, como porque era producto de una sociedad que los letrados porteños admiraban. Coincidentemente, fueron las novelas francesas las que lidiaron con temáticas más truculentas, como "Margarita Pusterla" de Cesare Cantú o "El Asesino de

\footnotetext{
${ }^{25} C d D, \mathrm{~N}^{\circ} 134,22$ de julio de 1866, p. 18.

${ }^{26} C d D, N^{\circ} 1,1^{\circ}$ de enero de 1864, p. 6.

${ }^{27} C d D, N^{\circ} 165,24$ de febrero de 1867.

${ }^{28} C d D, N^{\circ} 149,4$ de noviembre de 1866; $N^{\circ} 210,5$ de enero de 1868.

${ }^{29}$ Por ejemplo, La República, $N^{\circ} 37,13$ de febrero de 1873, p. 3.

${ }^{30} C d D, N^{\circ} 153,2$ de diciembre de 1866; $N^{\circ} 165,24$ de febrero de 1867.

${ }^{31} C d D, N^{\circ} 135,29$ de julio de 1866; N¹67, 10 de marzo de 1867.

${ }^{32} C d D, N^{\circ} 63,12$ de marzo de 1865, p. 177.
} 
Albertina Renouf" de Henrique Riviere. ${ }^{33}$ Una estrategia recurrente fue subrayar esos momentos violentos con ilustraciones. Imágenes como la debajo reproducida (Imagen 5) abrían un mundo de interpretaciones semióticas (particularmente el degüello tenía una carga simbólica poderosa en Buenos Aires asociada al federalismo de Rosas). Podrían incluso relacionarse con la consolidación en la década siguiente de la fotografía criminalística (Guerra, 2010), o con el desarrollo del atractivo escandaloso de las "páginas rojas" (Lyons, 1997). En un nivel más fundamental, es posible argumentar que su aspiración fue atrapar la atención de lector y generar una intriga que lo dirigiera hacia la entrega de la novela, cuya ubicación dentro del semanario se encontraba debidamente indicada en la leyenda de la imagen.

Imagen 5: "El verdugo, asiéndola por su negra cabellera, presentó a la muchedumbre una cabeza ensangrentada. Margarita Pusterla, paj. 430, col. $1^{\circ \prime \prime}$

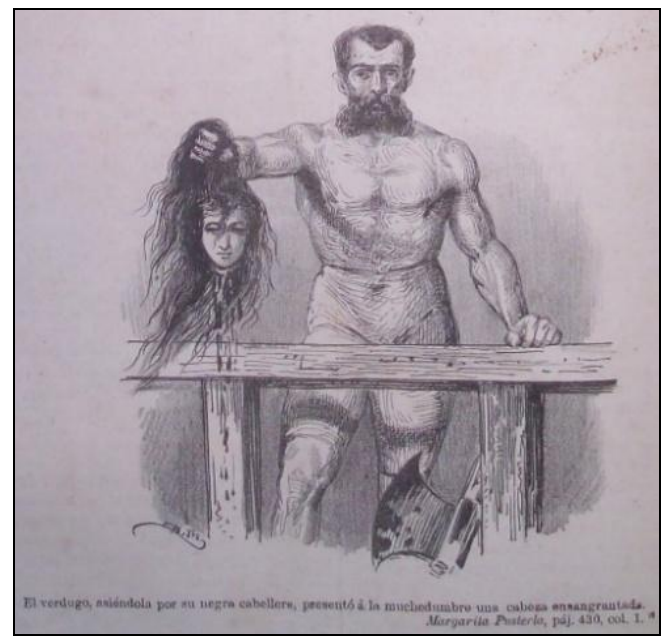

Fuente: $C d D, \mathrm{~N}^{\circ} 131,1^{\circ}$ de julio de 1867, p. 32.

\section{2. ¿Para quién era el Correo del Domingo?}

Si bien el desborde sensacionalista arriba descrito ofrece quizás el mejor ejemplo del juego entre texto e imagen buscado por las ilustraciones de Correo del Domingo, este también amenaza con contravenir parámetros establecidos por la redacción. Ya en el primer número Cantilo había extendido una garantía "á la madre de familia" que la moral "de sus hijas" estaría bien guardada en su "papel", ya que no habría allí textos que pudieran "infiltrar" los "corazones [con] sentimientos contrarios" a los inculcados por las señoras. Como correspondía a una "publicacion de esta clase", se velaría por inspirar "el sentimiento del progreso intelectual y del adelanto moral de nuestra sociedad". ${ }^{34}$

El recelo ante el folletín y sus contenidos tenía raíces profundas en los orígenes de la novela en la Europa del siglo XVIII (Littau, 2008), y gozaba de amplio consenso entre letrados y hombres de prensa porteños (Batticuore, 2017). Como denota el editorial de Cantilo, en Buenos Aires también se asoció a esos potenciales riesgos de manera predominante con la mujer y, en particular, con las más jóvenes. Debido a que se pensaba que ellas contaban con demasiado tiempo libre $y$, considerando que les era

\footnotetext{
${ }^{33} C d D, N^{\circ} 114,3$ de marzo de 1866; N83, 30 de junio de 1865.

${ }^{34} C d D, N^{\circ} 1,1^{\circ}$ de enero de 1864, p. 6.
} 
esquivo el don de la razón, se les atribuía cierta propensión por las pasiones desbocadas en la lectura. Tal era el caso de la hipotética "Enriqueta", imaginada en un ensayo del español Adolfo Llanos y Alcaraz reproducido en Correo del Domingo. Sus copiosas lecturas le hacían correr el riesgo de que el "mosáico de amantes de todos calibres, miraras ardientes, fracs arrebatadores, promesas, juramentos, despedidas" presentes en las novelas la hicieran "delira[r]", empujándola a tomar decisiones irracionales sobre su propio futuro. ${ }^{35}$

Ya en los 1830 se había establecido en la prensa porteña una estrecha relación entre la lectura por entretenimiento y los recursos formales asociados a dicha práctica, y un lectorado que se imaginaba joven y femenino. ${ }^{36}$ Un juicio que puede encontrarse reproducido posteriormente tanto en el folletín de los diarios, ${ }^{37}$ como en semanarios ilustrados previos. ${ }^{38}$ En este contexto se comprende que Cantilo construyera discursivamente al público deseado de su periódico como compuesto primordialmente por mujeres jóvenes lectoras, cuando su propuesta editorial se concentraba en crónicas de la sociabilidad porteña, modas, textos lúdicos y novelas por entregas ilustradas.

Correo del Domingo se caracterizó por tener una postura "permisiva" para con su público femenino imaginado, evitando "meterse á censor huraño", ofreciendo "figurines" y rindiéndose "á la moda". "¿Qué hacer si las niñas quieren llevar un parque en la cabeza?", se pregunta en un momento Cantilo. ${ }^{39}$ La publicación se presentó abierta a las mujeres como lectoras $y$, en su éxito, permite hipotetizar que para ese entonces la prensa ya se estaba configurando como un espacio apto para un público etario y genéricamente mixto (Poblete, 2000; Prieto, 2006). El semanario fue potencialmente un dispositivo nivelador y homogeneizador de competencias culturales diversas, lo que se evidencia en la reseñada mezcla de moda, novelas de folletín y el reportaje de la actualidad política y social. Si bien estos últimos eran discursos reservados para la prensa diaria orientada a varones ilustrados, aquí aparecían combinados con recursos formales que invitaban la lectura de un público feminizado, identificado mayormente con las jóvenes lectoras, que -se estimaba- solo leían para entretenerse.

Desde una perspectiva histórica, la apuesta de Cantilo por una propuesta editorial suntuosa y mayormente orientada a un lectorado cuanto menos mixto aparece como adelantada a su tiempo. De hecho, puede identificarse posteriormente a su desaparición un crecimiento exponencial de semanarios dedicados al "bello sexo", entre los que se destacan títulos como El Eco de las Niñas (1871-1872), Semanario de las Niñas (1872), El Recreo de las Niñas (1872) y Ecos Perdidos (1872), entre otros. El más exitoso de ellos, el esporádicamente ilustrado Correo de las Niñas (1868-¿?), gozó de gran aceptación, ya que fue serializado ininterrumpidamente durante por lo menos un lustro, y luego fue relanzado hasta bien entrados los años 1880. Incluso El Mosquito, recordado como un periódico satírico político, experimentó con variantes "literarias" durante ese período. ${ }^{40}$

\footnotetext{
${ }^{35} C d D, N^{\circ} 92,12$ de octubre de 1865, p. 634.

${ }^{36}$ La Moda, N ${ }^{\circ} 1,18$ de noviembre de 1837, p. 1.

${ }^{37}$ Diario de la Tarde, $\mathrm{N}^{\circ}$ 5.164, 14 de diciembre de 1848, p. 1.

${ }^{38}$ La llustración Argentina, Il época, N 1, 11 de diciembre de 1853, p. 12.

${ }^{39} C d D, \mathrm{~N}^{\circ} 89,10$ de septiembre de 1865, p. 586.

${ }^{40}$ El Mosquito, $\mathrm{N}^{\circ} 364,9$ de enero de 1870.
} 
Un indicador de la aceptación que gozó la propuesta editorial fue la constancia que presentó. Su puesta en página permaneció sin cambios hasta su último año, e incluso entonces solo se incorporó una tercera columna a fines de aumentar la cantidad de texto impreso. ${ }^{41}$ Esta estabilidad tipográfica fue atípica en la prensa porteña del siglo XIX, incluso cuando los impresos que se consideraba que tenían buenas ventas se veían sometidos a cambios regulares formales y mudanzas de imprenta.

Podríamos decir que Correo del Domingo fue, incluso, demasiado adelantado. Su éxito fue la primera prueba de que Buenos Aires estaba lista para sostener un periódico semanal ilustrado. Cantilo utilizó la capacidad de su Imprenta del Orden para hacer circular una publicación ambiciosa que combinó la suma del repertorio de recursos disponibles para favorecer la lectura por entretenimiento, lo que probó ser una fórmula ganadora. En ocasión del número centenario, él dio cuenta de la propia sorpresa en un breve texto donde se enorgulleció de ser una de las "pocas publicaciones de este jénero logran vencer las dificultades con que tienen que luchar los periódicos literarios", y afirmó con "voluntad decidida" poder campear "los quebrantos experimentados" en la labor editorial, postergando "esperanzas de una vida propia para mas adelante". ${ }^{42}$

Sin embargo, el mercado editorial en Buenos Aires seguía acusando limitaciones comerciales y materiales. Por ejemplo, las publicaciones periódicas continuaban invariablemente atadas a la venta por suscripción. Si hemos de creer a Cantilo, no se vendieron "números sueltos, por cuanto eso dejaría truncas las colecciones y no permitiría encuadernar las novelas que ocupen varios números". Una actitud rígida que puede asociarse a lo ambicioso de la apuesta editorial, que necesariamente dependía del dinero adelantado por las suscripciones para poder solventar los altos costos de impresión (Gentile, 2002). Como contraprestación, se ofreció la promesa que el primer número sería "distribuido profusamente". ${ }^{43}$

Las "mil quinientas bocas" de suscriptores presumidos en el editorial inaugural son la única cifra con la que contamos. Un número que, de ser veraz, representa un gran salto en relación con los cerca de cuatrocientos suscriptores que atribuyó Hortelano (1936) a La llustración Argentina una década atrás (p. 238). Pero, aparentemente, era una cantidad insuficiente para resolver los problemas materiales que aquejaban a la prensa ilustrada. Desde el comienzo, la "Redacción" advirtió "las dificultades con que tienen que luchar los periódicos literarios", pidiendo disculpas por la ausencia de más "grabados en madera", que se atribuía a que "al intelijente artista le ha faltado el tiempo necesario esta vez". ${ }^{44}$ A la hora de ofrecer explicación al finalizar la publicación, Cantilo nuevamente adujo como causal las "dificultades que se tocan respecto de la parte ilustrada". Con optimismo anunció entonces que se reanudaría la colección más adelante, tras "haber allanado" los obstáculos, ${ }^{45}$ lo que nunca sucedería.

Estas intervenciones esporádicas invitan a deducir que, incluso un semanario exitoso como lo fue Correo del Domingo sufría limitaciones impuestas por la realidad material del mercado de la prensa. La asociación con la litografía funcionó a favor como

\footnotetext{
${ }^{41} C d D$, I época, $\mathrm{N}^{\circ} 176,12$ de mayo de 1867.

${ }^{42} C d D, N^{\circ} 100,26$ de noviembre de 1865, p. 761.

${ }^{43} C d D, N^{\circ} 1,1^{\circ}$ de enero de 1864, p. 6.

${ }^{44} C d D, N^{\circ} 1,1^{\circ}$ de enero de 1864, p. 6.

${ }^{45} C d D, \mathrm{~N}^{\circ} 210,5$ de enero de 1868, p. 32.
} 
un punto de atracción, pero al mismo tiempo condicionó al impreso a una técnica compleja y costosa que elevaba exponencialmente los costos. A modo de referencia, los treinta pesos mensuales que costaba la suscripción igualaban aquella del diario El Nacional y era cincuenta por ciento más cara que la del también ilustrado El Mosquito. ${ }^{46}$ La venta por suscripción ató la liquidez de la empresa al número de suscriptores, sin otro respaldo, ya que por entonces los semanarios no estilaban aún la inclusión de publicidad. Sin embargo, las soluciones a estos problemas comenzaban a ser exploradas de manera contemporánea por otros impresores y editores. Por ejemplo, a fines de los años 1860 aparecieron los primeros periódicos que experimentaron con la venta libre por "voceo", o que incluyeron publicidades ilustradas (Cavalaro, 1996; Roman, 2010).

Luego de cuatro años de suceso y complicaciones materiales, Correo del Domingo dejó de existir. Si el éxito previo del semanario prueba la aceptación de una prensa ilustrada orientada a la lectura por entretenimiento de parte de un público lector que se imaginaba mixto, su final evidencia los límites que los costos de producción, un modelo comercial que no contemplaba la publicidad y la distribución por suscripción, imponían a los emprendimientos editoriales porteños en un momento de expansión lectora.

\section{A modo de conclusión}

El desarrollo generoso de los recursos formales que entendemos como orientados a la lectura por entretenimiento en Correo del Domingo representó, como afirmamos al comienzo, una novedad dentro de la prensa porteña. La última página se consolidó en un espacio de misceláneas que invitaban a la lectura breve, diversa y fragmentada. Donde no solo se recurrió a las variedades, sino que se sumaron de manera recurrente los textos lúdicos de las "Charadas" y los "Enigmas". Lo mismo se puede decir de la novela por entregas que, liberada de la delimitación formal del rodapié del diario, se multiplicó al punto de ocupar hasta dos tercios del semanario.

Sobre esta base anclada en probados recursos se desplegó un uso intensivo de impresiones litográficas. Si bien, como vimos, distó de ser un aporte inédito, la apuesta editorial se distinguió tanto por la cantidad como la calidad de imágenes reproducidas. Hipotetizamos que la oferta visual fue recibida con entusiasmo porque, por un lado, fue interpretada como el mayor esfuerzo realizado hasta el momento por satisfacer el "deseo de ver y poseer imágenes" de los lectores porteños (Szir, 2010, p. 1) y, por otro, representó por primera vez a la sociabilidad y a las prácticas urbanas en Buenos Aires a la manera de las litografías importadas del otro lado del Atlántico.

Es suma, Correo del Domingo se destacó por construir una propuesta editorial novedosa a partir de un repertorio editorial disponible en la prensa contemporánea, donde dichos recursos formales fueron expandidos y desarrollados a lo largo de dieciséis páginas. Potencialmente amplió el lectorado de la prensa, al combinar imágenes de moda y novelas por entregas que se pensaban orientadas a la mujer lectora, con el reportaje visual de una realidad política y social que en los periódicos diarios podía leerse, pero no verse. Aun así, la publicación encontró finalmente una

\footnotetext{
${ }^{46}$ El Nacional, $\mathrm{N}^{\circ} 6.091,5$ de noviembre de 1866, p. 1. El Mosquito, $\mathrm{N}^{\circ} 215,1^{\circ}$ de septiembre de 1867, p. 1.
} 
Labra,D. Un entretenimiento ilustrado. Correo del Domingo (1864-1868) y la consolidación de la prensa ilustrada en Buenos Aires

abrupta conclusión en limitaciones técnicas y comerciales de las cuales el mercado editorial porteño estaba tan cerca de poder librarse.

\section{Referencias bibliográficas}

1. Alarcón, P. de (1861). De Madrid a Nápoles: pasando por París, Ginebra, el Mont Blanc, el Simplon, el Lago Mayor, Turín, Pavía, Milán, el Cuadrilátero, Venecia, Bolonia, Módena, Parma, Génova, Pisa, Florencia, Roma y Gaeta: viaje de recreo, realizado durante la guerra de 1860 y sitio de Gaeta en 1861. Imprenta y librería de Gaspar y Roig.

2. Barthes, R. (1986). Retórica de la imagen. En Lo obvio y lo obtuso. Imágenes, gestos, voces (pp. 29-48). Paidós.

3. Barthes, R. (2003). Estructura del 'suceso'. En Ensayo Críticos (pp. 259-272). Seix Barral.

4. Batticuore, G. (2017). Lectoras del siglo XIX. Imaginarios y prácticas en la Argentina. Ampersand.

5. Cavalaro, D. (1996). Las revistas ilustradas en el siglo XIX. Asociación Argentina de Editores de Revistas.

6. Chartier, R. (1992). El mundo como representación. Gedisa.

7. Crary, J. (2001). Suspensions of perception: attention, spectacle, and modern culture. MIT Press.

8. Gentile, M. B. (2002). La prensa insurgente en la Independencia Hispanoamericana. 1808-1830 [tesis doctoral, Universidad Nacional de La Plata, tesis no publicada].

9. Goldgel, V. (2010). Caleidoscopios del saber. El deseo de variedad en las letras latinoamericanas del siglo XIX. Estudios. Revista de investigaciones literarias y culturales, 18 272-295. https://biblat.unam.mx/hevila/EstudiosRevistadeinvestigacionesliterariasycultura les/2010/vol18/no36/2.pdf

10. Guerra, D. F. (2010, 28 de octubre). Éramos pocos y parió el aura: fotografía y políticas de la imagen en los albores de la reproductibilidad masiva en la Argentina. Caras y Caretas, 1898-1910 [ponencia]. III Seminario Internacional Políticas de la Memoria. Buenos Aires, Argentina. 
Labra,D. Un entretenimiento ilustrado. Correo del Domingo (1864-1868) y la consolidación de la prensa ilustrada en

11. Hallstead, S. (2005). Fashion Nation: The Politics of Dress and Gender in 19th Century Argentine Journalism (1829-1880) [tesis doctoral, University of Pittsburgh] http://d-scholarship.pitt.edu/6634/

12. Hortelano, B. (1936). Memorias. Espasa Calpe.

13. Lettieri, A. (2006). La construcción de la República de la opinión. Buenos Aires frente al interior en la década de 1850. Prometeo.

14. Littau, K. (2008). Teorías de la lectura. Libros, cuerpos y bibliomanía. Manantial.

15. Losada, L. (2006). Sociabilidad, distinción y alta sociedad en Buenos Aires: Ios clubes sociales de la elite porteña (1880-1930). Desarrollo Económico, 1 (180), 547-572. https://doi.org/10.2307/3655880

16. Lyons, M. (1997). Los nuevos lectores del siglo XIX: mujeres, niños, obreros. En G. Cavallo y R. Chartier (Dirs.) Historia de la lectura en el mundo occidental (pp. 473-524). Taurus.

17. Malosetti Costa, L. y Gené, M. (Comps.) (2009). Impresiones porteñas. Imagen y palabra en la historia cultural de Buenos Aires. Edhasa.

18. Maturana, C. L. (2009). La Comedia de Magia y los efectos visuales de la era pre-cinematográfica en el siglo XIX en Chile. Aisthesis, 1 (45), 82-102. http://dx.doi.org/10.4067/S0718-71812009000100006

19. Molina, H. B. (2011). Como crecen los hongos. La novela argentina entre 1838 y 1872. Teseo.

20. Parada, A. (2007). Cuando los lectores nos susurran. Libros, lecturas, bibliotecas, sociedad y prácticas editoriales en la Argentina. Universidad de Buenos Aires.

21. Pas, H. (2011). La seducción de las imágenes. El ingreso de la litografía y los nuevos modos de publicidad en Latinoamérica. Caracol, 1 (2), 10-41. https://doi.org/10.11606/issn.2317-9651.v0i2p10-41

22. Pas, H. (2014). Leer (con) imágenes. Litografías y prensa periódica en los procesos de lectura y escritura a mediados del siglo XIX en el Río de la Plata. En V. Delgado, A. Mailhe y G. Rogers (Coords). Tramas impresas: Publicaciones periódicas argentinas (XIX-XX) (pp. 64-79). Universidad Nacional de La Plata. http://sedici.unlp.edu.ar/handle/10915/45400

23. Pas, H. (2016). Variedades y escritura periódica. Notas para una historia del folletín en el Río de la Plata. En V. Delgado y G. Rogers (Eds.) Tiempos de papel: 
publicaciones periódicas argentinas (siglos $X I X-X X)$ (pp. 54-66). Universidad Nacional de La Plata. http://sedici.unlp.edu.ar/handle/10915/59632

24. Poblete, J. (2000). Lectura de la sociabilidad y sociabilidad de la lectura: la novela y las costumbres nacionales en el siglo XIX. Revista de Crítica Literaria Latinoamericana, 1 (52), 11-34. https://doi.org/10.2307/4531118

25. Prieto, A. (2006). El discurso criollista en la formación de la Argentina moderna. Siglo XXI.

26. Rocchi, F. (2006). Chimneys in the desert. Industrialization in Argentina during the export boom years, 1870-1930. Stanford University Press.

27. Rogers, G. (2008). Caras y Caretas: cultura, política y espectáculo en los inicios del siglo XX argentino. Editorial de la Universidad Nacional de La Plata. https://doi.org/10.35537/10915/15933

28. Roman, C. (2010). La prensa satírica Argentina del Siglo XIX: palabras e imágenes [tesis doctoral, Universidad de Buenos Aires]. http://repositorio.filo.uba.ar/handle/filodigital/1613

29. Szir, S. (2010). De la cultura impresa a la cultura de lo visible. Las publicaciones periódicas ilustradas en Buenos Aires en el Siglo XIX. Colección Biblioteca Nacional Estudios, $18(36), 1-31$.

30. Szir, S. (2016). Propósitos representativos nacionales, 'bellas artes' y reproducción de imágenes en La llustración Argentina (1881-1887). En V. Delgado y G. Rogers (Eds.) Tiempos de papel: publicaciones periódicas argentinas (siglos $X I X-X X$ ) (pp. 38-53). Universidad Nacional de La Plata. http://sedici.unlp.edu.ar/handle/10915/59632

31. Szir, S. (2017). Imágenes y tecnologías entre Europa y la Argentina. Migraciones y apropiaciones de la prensa en el siglo XIX. Nuevo Mundo Mundos Nuevos, Images, mémoires et sons, s/p. https://doi.org/10.4000/nuevomundo.70851

32. Telesca, A. M. y Amigo, R. (1997). La curiosidad de los porteños. El público y los temas de las vistas ópticas de representación en el Estado de Buenos Aires (1852-1862). En Historia de la Fotografía. Memoria del V Congreso de Historia de la Fotografía en la Argentina (pp. 33-36). Comité Permanente para los Congresos de Historia de la Fotografía en Argentina.

33. Williams, R. (1982). Dream Worlds: Mass consumption in late nineteenthcentury France. University of California Press. 